\title{
High-performance iron-based ORR catalysts synthesized via chemical vapor deposition
}

\author{
Li Jiao ${ }^{1}$, Jingkun $\mathrm{Li}^{2}$, Lynne Larochelle Richard ${ }^{3}$, Thomas Stracensky ${ }^{3}$, Ershuai Liu ${ }^{3}$, \\ Qiang Sun ${ }^{3}$, Moulay-Tahar Sougrati ${ }^{2}$, Zipeng Zhao ${ }^{4}$, Fan Yang ${ }^{5}$, Sichen Zhong ${ }^{5}$, Hui Xu ${ }^{5}$, \\ Sanjeev Mukerjee ${ }^{3}$, Yu Huang, ${ }^{4,6}$, Deborah J. Myers*,7, Frédéric Jaouen*,2, and Qingying \\ $\mathrm{Jia}^{*, 3}$
}

${ }^{1}$ Department of Chemical Engineering, Northeastern University, Boston, Massachusetts, 02115, United States

${ }^{2}$ Institut Charles Gerhardt Montpellier, UMR 5253, CNRS, Université Montpellier, ENSCM, Place Eugène Bataillon, 34095 Montpellier cedex 5, France

${ }^{3}$ Department of Chemistry and Chemical Biology, Northeastern University, Boston, Massachusetts, 02115, United States

${ }^{4}$ Department of Materials Science and Engineering, University of California, Los Angeles, California, 90095, United States

${ }^{5}$ Giner, Inc, Newton, Massachusetts, 02466, United States.

${ }^{6}$ California NanoSystems Institute (CNSI), University of California, Los Angeles, California, 90095

${ }^{7}$ Chemical Sciences and Engineering Division, Argonne National Laboratory, Lemont, Illinois, 60439, United States

*Correspondence authors. Emails: dmyers@anl.gov (D. M.);

frederic.jaouen@umontpellier.fr (F. J.); q.jia@northeastern.edu (Q. J.) 


\begin{abstract}
A Fe-N-C catalyst was synthesized via chemical vapor deposition (CVD) of gas phase $\mathrm{FeCl}_{3}$ onto a metal organic framework (MOF)-derived N-doped carbon (N-C) substrate at $750{ }^{\circ} \mathrm{C}$. This catalyst exhibits an unprecedented current density of 0.033 $\mathrm{mA} \cdot \mathrm{cm}^{-2}$ at $0.90 \mathrm{~V}_{\text {iR-free }}$ (IR-corrected) and $0.044 \mathrm{~mA} \cdot \mathrm{cm}^{-2}$ at $0.89 \mathrm{~V}_{\text {iR-free }}$ in a $\mathrm{H}_{2}-\mathrm{O}_{2}$ proton exchange membrane fuel cell under 1.0 bar and $80{ }^{\circ} \mathrm{C}$ conditions. The exceptional ORR activity of this catalyst is attributed to the ultra-high density of the Fe(II)- $\mathrm{N}_{4}$ sites. The high density of $\mathrm{Fe}(\mathrm{II})-\mathrm{N}_{4}$ sites is realized by CVD that allows for the ready formation of $\mathrm{Fe}(\mathrm{II})-\mathrm{N}_{4}$ sites via direct incorporation of gas phase $\mathrm{FeCl}_{3}$ into microporous $\mathrm{N}$-C defects at relatively low temperatures. At these low temperatures, the doped $\mathrm{N}$ and $\mathrm{Fe}(\mathrm{II})-\mathrm{N}_{4}$ are better preserved as compared to those in previous Fe-N-C catalysts synthesized via pyrolysis of the mixture of $\mathrm{Fe}, \mathrm{N}$, and $\mathrm{C}$ precursors at $1000 \pm 100{ }^{\circ} \mathrm{C}$.
\end{abstract}


Commercialization of hydrogen fuel cell vehicles was initiated in 2014 in Japan and thus far has spread to only few additional countries. Global commercialization of hydrogen fuel cell vehicles requires significant reductions in the overall cost of the proton exchange membrane fuel cell (PEMFC) stack (1). The prohibitively high cost of the stack originates largely from the high platinum loading in the cathode electrode needed to effectively promote the sluggish oxygen reduction reaction (ORR). Reduce the Pt loading by improving the inherent ORR activity of Pt-catalysts, or replacing Pt with inexpensive and earth-abundant platinum group metal (PGM) free materials are the two major routes to reduce the stack cost. The major challenge of the PGM-free route is to develop PGMfree catalysts with the ORR activity comparable to that of Pt. The U.S. Department of Energy (DOE) has set a 2020 ORR activity target for PGM-free catalysts in the fuel cell environment as a current density of $0.044 \mathrm{~A} \cdot \mathrm{cm}^{-2}$ under 1.0 bar $\mathrm{H}_{2}-\mathrm{O}_{2}$ at $0.90 \mathrm{~V}_{\text {iR-free }}(i \mathrm{R}$ corrected; $i$, current; R, resistance), which is comparable to the activity target for PGM catalysts (0.44 A'mgg ${ }^{-1}$ at a loading of $\left.0.1 \mathrm{mg}_{\mathrm{Pt}} \cdot \mathrm{cm}^{-2}\right)(2)$. However, the highest ORR activity for PGM-free catalysts reported thus far is $\sim 0.022 \mathrm{~A} \cdot \mathrm{cm}^{-2}$ at $0.90 \mathrm{~V}_{\text {iR-free }}$ in $\mathrm{H}_{2}-\mathrm{O}_{2}$ PEMFCs (2, 3), only half the DOE 2020 target. The substantial activity gap between the PGM-free and PGM catalysts accounts partly for the substantially lower power density delivered by PGM-free catalysts in practical $\mathrm{H}_{2}$-air PEMFCs $\left(<0.57 \mathrm{~W} \cdot \mathrm{cm}^{2}\right)(4)$ than that of PGM catalysts $\left(>1 \mathrm{~W} \cdot \mathrm{cm}^{2}\right)$.

The most active PGM-free ORR catalysts are pyrolyzed transition metal-nitrogen-carbon (M-N-C, M=Fe or Co) catalysts (4-10). This group of catalysts originated from the pioneering work by Jasinski (11) who demonstrated cobalt phthalocyanine (CoPc) was ORR active in alkaline media. In the 1980s Yeager et al. (12) proved that pyrolyzing the 
mixture of $\mathrm{M}, \mathrm{N}$, and $\mathrm{C}$ precursors at elevated temperature can produce highly active $\mathrm{M}$ $\mathrm{N}-\mathrm{C}$ catalysts for the ORR in acidic media. Since then, tremendous effort has been devoted to improving the M-N-C catalysts by varying the type and composition of precursors and tuning the pyrolysis process. Highly active Fe-N-C catalysts have been produced by various methods and precursors such as polymer and organic compounds (5, 13), silica templating $(3,14)$, and Zn-based metal organic framework (MOF) $(8,10,15$, 16), etc. All these methods, however, incorporate the core feature of the pyrolysis route initiated by Yeager et al. (12): pyrolyzing the mixture of Fe, $\mathrm{N}$, and $\mathrm{C}$ precursors in the temperature range of $900-1100{ }^{\circ} \mathrm{C}$. Moreover, all the pyrolyzed Fe-N-C catalysts likely share the same Fe- $\mathrm{N}_{4}$ moiety responsible for their high ORR activities in acid $(5,7,15)$. The ORR activity gap between these Fe-N-C catalysts and that of state-of-the-art Pt or Pt alloy catalysts supported on high surface area carbon (Pt/C) is mainly caused by the relatively low inherent ORR activity of the Fe- $\mathrm{N}_{4}$ moiety and the low density of $\mathrm{Fe}-\mathrm{N}_{4}$ sites, both of which are approximately an order of magnitude lower than that of Pt/C. (17-19). The Fe- $\mathrm{N}_{4}$ site density saturates at a very low Fe content $(<2 \mathrm{wt} \%)$ in the Fe-NC catalysts $(8,20)$, whereas the Pt content in Pt/C is typically in the range of 20-50 wt\% (21). Closing the ORR activity gap between the Fe-N-C and Pt/C catalysts, thus, relies heavily on improving the inherent ORR activity of the Fe-site(s), and/or increasing the Fe- $\mathrm{N}_{4}$ site density. Despite substantial efforts in these two areas, significant breakthroughs have yet to be achieved.

Recently, we demonstrated that the Fe- $\mathrm{N}_{4}$ site can be formed via non-contact pyrolysis wherein the Fe precursor is not in physical contact with the $\mathrm{N}$ and $\mathrm{C}$ precursors during pyrolysis (22). Inspired by this proof-of-concept, herein we report a highly active Fe-N-C 
catalyst synthesized via chemical vapor deposition (CVD) wherein gas phase $\mathrm{FeCl}_{3}$ is deposited onto a N-doped carbon ( $\mathrm{N}-\mathrm{C})$ substrate, leading to the formation of abundant Fe- $\mathrm{N}_{4}$ sites at a relatively low temperature of $750{ }^{\circ} \mathrm{C}$. This catalyst exhibits an ORR activity of $0.033 \mathrm{~mA} \cdot \mathrm{cm}^{-2}$ at $0.90 \mathrm{~V}_{\text {iR-free }}$ and $0.044 \mathrm{~mA} \cdot \mathrm{cm}^{-2}$ at $0.89 \mathrm{~V}_{\text {iR-free }}$ in a $\mathrm{H}_{2}-\mathrm{O}_{2}$ PEMFC. Multi-component characterizations show that the unprecedent ORR activity arises mainly from the ultra-dense electrochemically active $\mathrm{Fe}-\mathrm{N}_{4}$ sites.

Anhydrous $\mathrm{FeCl}_{3}$ (99\%, Sigma-Aldrich) was chosen as the Fe precursor owing to its low boiling point of $\sim 316{ }^{\circ} \mathrm{C}$, which allows for the formation of gas phase $\mathrm{FeCl}_{3}$ at relatively low temperature. The N-C substrate was prepared by mixing the homemade zeolitic imidazolate framework eight (ZIF-8) and 1,10 phenanthroline via dry ball milling, followed by pyrolysis under Ar at $1050{ }^{\circ} \mathrm{C}$ (details given in the Experimental Section). The $\mathrm{FeCl}_{3}(110 \mathrm{mg})$ and $\mathrm{N}-\mathrm{C}(110 \mathrm{mg})$ substrate were placed in two different boats situated $1 \mathrm{~cm}$ apart in a quartz tube and pyrolyzed at $750{ }^{\circ} \mathrm{C}$ for three hours, followed by cooling to room temperature within the tube furnace. The collected powders (labelled as FeNC-CVD-750) were subjected to multi-technique characterization and PEMFC evaluation.

The rotating disk electrode (RDE) ORR voltammetric curve of FeNC-CVD-750 with a catalyst loading of $800 \mu \mathrm{g} \cdot \mathrm{cm}^{-2}$ in oxygen-saturated $0.5 \mathrm{M} \mathrm{H}_{2} \mathrm{SO}_{4}$ displayed in Figure $1 \mathrm{~A}$ exhibits a well-defined mass transport limiting current density, and a half wave potential of $0.82 \mathrm{~V}$ (all potentials reported here are versus the reversible hydrogen electrode), which is among the highest reported for a PGM-free catalyst in RDE (23). The cyclic voltammetry $(\mathrm{CV})$ (Figure $1 \mathrm{~B}$ ) exhibits prominent $\mathrm{Fe}^{3+/ 2+}$ redox peaks around $0.64 \mathrm{~V}$ which have been previously observed for Fe-N-C catalysts (24), indicating the presence 
of abundant electrochemically-active $\mathrm{Fe}-\mathrm{N}_{4}$ sites. In addition, the $C V$ has a high capacitance of $0.24 \mathrm{~F} \cdot \mathrm{mg}^{-1}$, corresponding to a high electrochemical surface area (ECSA) of $1176 \mathrm{~m}^{2} \cdot \mathrm{g}^{-1}$, assuming a specific capacitance of $204 \mathrm{mF} \cdot \mathrm{m}^{-2}(15)$. The combination of abundant electroactive Fe- $\mathrm{N}_{4}$ sites and high ECSA result in the high ORR activity observed for this catalyst. Indeed, in an $\mathrm{H}_{2}-\mathrm{O}_{2}$ PEMFC the FeNC-CVD-750 delivers a current density of $0.033 \mathrm{~mA} \cdot \mathrm{cm}^{-2}$ at a reference voltage of $0.9 \mathrm{~V}_{\text {iR-free, }}$ which is 1.5 times the highest current density reported to date for PGM-free catalysts in an $\mathrm{H}_{2}-\mathrm{O}_{2}$ PEMFC (2, 3). It also delivers a current density of $0.044 \mathrm{~mA} \cdot \mathrm{cm}^{-2}$ at $0.89 \mathrm{~V}_{\text {iR-free, }}$, only $0.01 \mathrm{~V}$ lower than the DOE 2020 target (2).
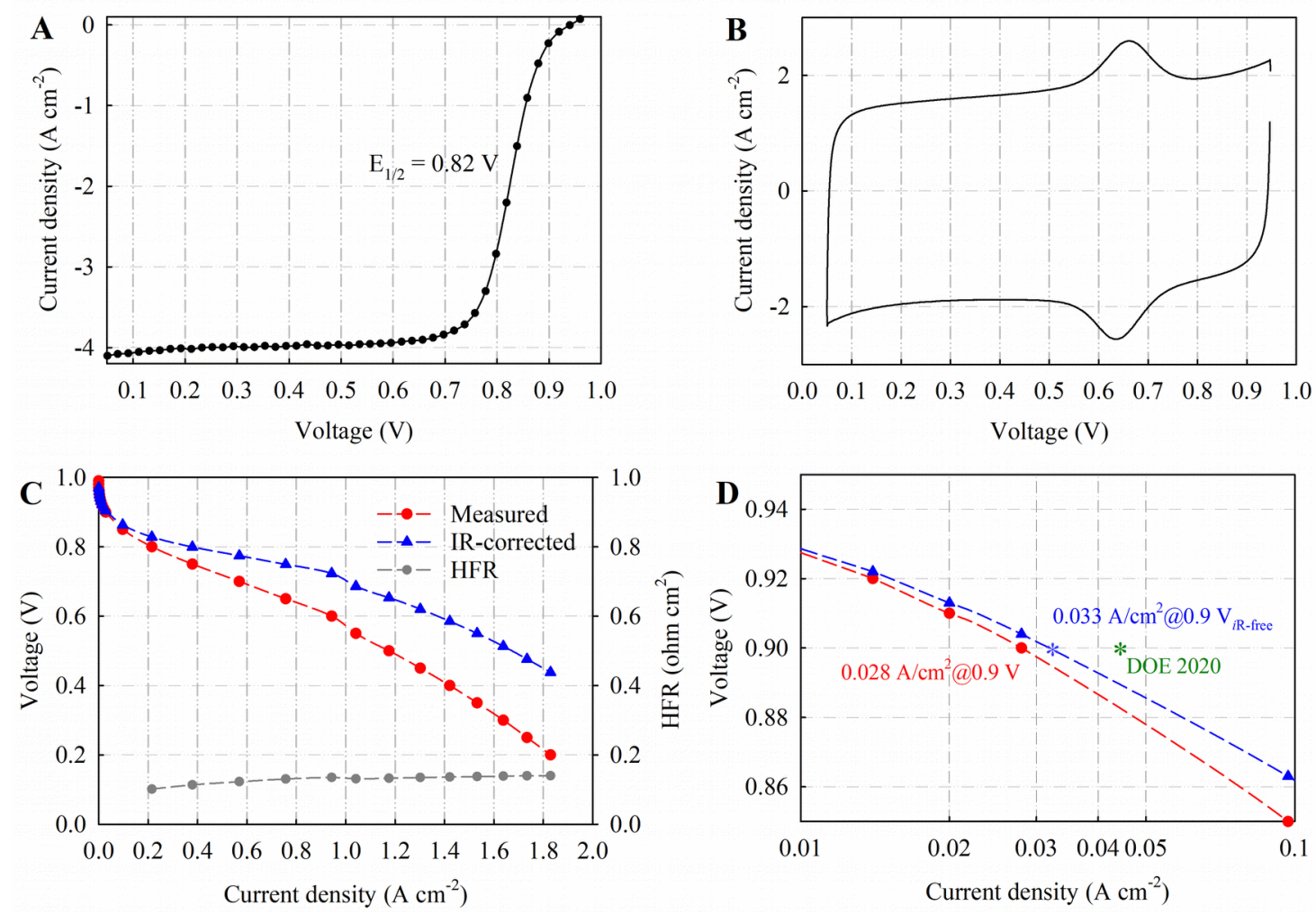

Figure 1. (A) ORR performance of the FeNC-CVD-750 catalyst. Steady-state RDE polarization in $\mathrm{O}_{2}$-saturated, room-temperature $0.5 \mathrm{M} \mathrm{H}_{2} \mathrm{SO}_{4}$ using a rotation rate of $900 \mathrm{rpm}$, 20-mV potential steps from 0.05 to $0.95 \mathrm{~V}$, and a 25-s potential hold time at each step. (B) Cyclic voltammogram $(\mathrm{CV})$ of the same catalyst taken after the ORR polarization curve presented in (A) and after deaerating the room-temperature electrolyte. CV scan rate was $10 \mathrm{mV} \cdot \mathrm{s}^{-1}$. (C) $\mathrm{H}_{2}-\mathrm{O}_{2} \mathrm{PEMFC}$ polarization curves with and without $i$ R-correction. Cathode: $\sim 6.0 \mathrm{mg} \cdot \mathrm{cm}^{-2}$ of the catalyst; Anode: $0.3 \mathrm{mg}_{\mathrm{Pt}} \mathrm{Cm}^{-2} \mathrm{Pt} / \mathrm{C}$; Membrane: Nafion 212; $200 \cdot \mathrm{mL} / \mathrm{min}^{-1}$ gas fed at both anode $\left(\mathrm{H}_{2}\right)$ and cathode 
$\left(\mathrm{O}_{2}\right)$ with $100 \% \mathrm{RH}$, and 1.0 bar partial pressure each side; cell $80^{\circ} \mathrm{C}$; electrode area $5 \mathrm{~cm}^{2}$. (D) the Tafel plot derived from the $i \mathrm{R}$-corrected ORR polarization curve displayed in (C) to illustrate the measured ORR activity at $0.9 \mathrm{~V}$ versus the DOE 2020 target.

To understand the structural origins of the exceptional ORR activity of the FeNC-CVD750 catalyst, multi-technique characterizations were conducted to reveal its atomic-level structure. Figure 2 presents the transmission electron microscopy (TEM) images of the in-house ZIF-8 (Figure 2A), the ZIF-8-derived N-C substrate upon pyrolysis (Figure 2B), and the Fe-N-C produced by CVD from $\mathrm{FeCl}_{3}$ and the N-C substrate (Figure 2C and 2D). The in-house ZIF-8 has a uniform ZIF crystal size of $40 \mathrm{~nm}$ (Figure 2A). Upon pyrolysis, the crystal structure largely collapsed leading to the formation of an amorphous carbon matrix with a Brunauer-Emmett-Teller (BET) area of $630 \mathrm{~m}^{2} \cdot \mathrm{g}^{-1}$. As shown in Figure 2, the carbon matrix of FeNC-CVD-750 exhibited a layered structure. The BET area of FeNC-CVD-750 is $~ 970 \mathrm{~m}^{2} \cdot \mathrm{g}^{-1}$, comparable to the ECSA $\left(1176 \mathrm{~m}^{2} \cdot \mathrm{g}^{-1}\right)$ derived from the CV capacitance. The high resolution TEM of FeNC-CVD-750 revealed the presence of amorphous iron clusters (Figure 2D).

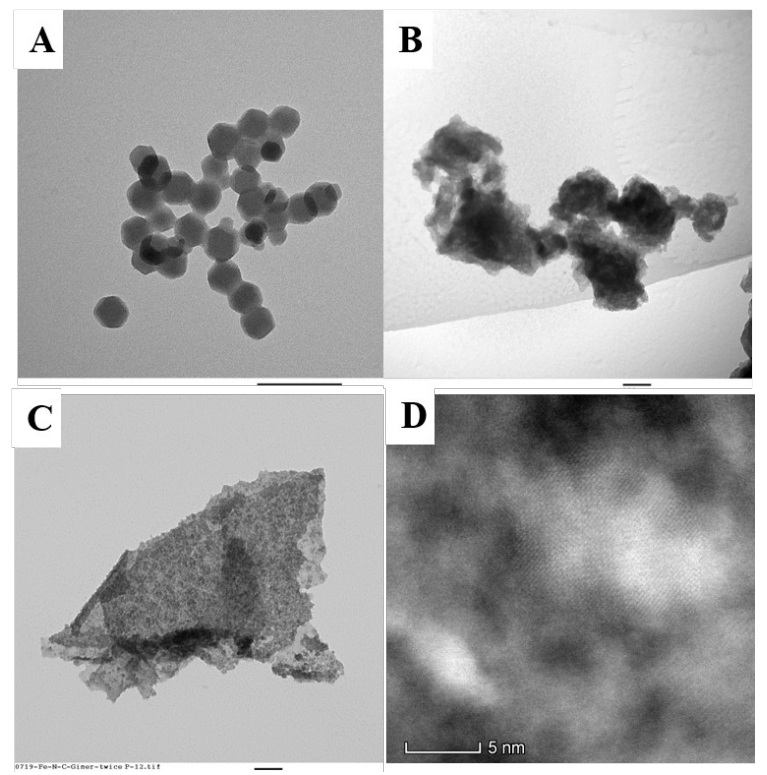

Figure 2. TEM images of the (A) in-house ZIF-8, (B) ZIF-8 derived N-C substrate, and (C and D) the FeNC-CVD-750 catalyst. The bars in A, B, and C represent a $100 \mathrm{~nm}$ scale. 
The X-ray diffraction (XRD) pattern of the FeNC-CVD-750 shows a relatively broad peak centered at approximately 20 degree, verifying the amorphous nature of the carbon matrix (Figure 3A). In addition, the absence of the XRD signals of crystalline iron species indicates that the iron clusters in FeNC-CVD-750 seen by TEM are highly amorphous. The local structure of the iron species in FeNC-CVD-750 was further explored by ex situ X-ray absorption spectroscopy (XAS). The X-ray near edge structure (XANES) spectrum of FeNC-CVD-750 nearly overlaps that of the Iron(III) phthalocyanine tetrasulfonic acid (Fe(III)Pc- $\mathrm{O}_{2}$ ) (80\%, Sigma Aldrich), and does not resemble that of the Iron(II) phthalocyanine (Fe(II)Pc) (Figure 3B). This result suggests that the bulk average oxidation state of the iron species in FeNC-CVD-750 is close to 3+. Meanwhile, the Fourier Transform of the extended X-ray absorption fine structure (FTEXAFS) spectrum of FeNC-CVD-750 exhibits one prominent peak at approximately 1.6 $\AA$ (Figure 3C). This peak is located slightly to higher radial distance than the first shell Fe-N peak of $\mathrm{Fe}(\mathrm{II}) \mathrm{Pc}$ and the $\mathrm{Fe}(\mathrm{III}) \mathrm{Pc}-\mathrm{O}_{2}$ peak arising from Fe- $\mathrm{N}_{4}$ and $\mathrm{Fe}-\mathrm{O}_{2}$ scattering. The EXAFS fitting (Figure 3D) of this peak gives an Fe-N/O (scattering from $\mathrm{N}$ and $\mathrm{O}$ cannot be distinguished by XAS) coordination number of $4.7 \pm 0.5$ and an average bond distance of $2.02 \pm 0.01 \AA$. This bond distance is much longer than the Fe-N bond distance of Fe(II)Pc (1.93 $\AA)$ (20), but comparable to the Fe-N/O bond distances reported previously for pyrolyzed Fe-N-C catalysts under ex situ conditions $(15,25)$. This result suggests that FeNC-CVD-750 contains the same Fe- $\mathrm{N}_{4}$ active sites as other pyrolyzed Fe$\mathrm{N}-\mathrm{C}$ catalysts, despite the different synthesis route. The absence of prominent Fe-Fe scattering peaks from inorganic iron species such as nanoparticles, oxides, carbides in the FT indicates that the inorganic iron species in FeNC-CVD-750 are highly amorphous, in 
agreement with XRD and TEM results, and that the fraction of Fe in these types of coordination environment is relatively low. The overall Fe content in FeNC-CVD-750 is around $2.6 \mathrm{wt} \%$ as estimated from the edge step of the XANES spectrum. Since the content of inorganic Fe species in FeNC-CVD-750 is relatively low, this result indicates that FeNC-CVD-750 contains dense Fe- $\mathrm{N}_{4}$ sites, consistent with the prominent redox $\mathrm{Fe}^{3+/ 2+}$ peaks present in the $C V$ (Figure 1B). Therefore, we tentatively attribute the exceptional ORR activity of FeNC-CVD-750 to the high density of the Fe- $\mathrm{N}_{4}$ sites available for ORR.
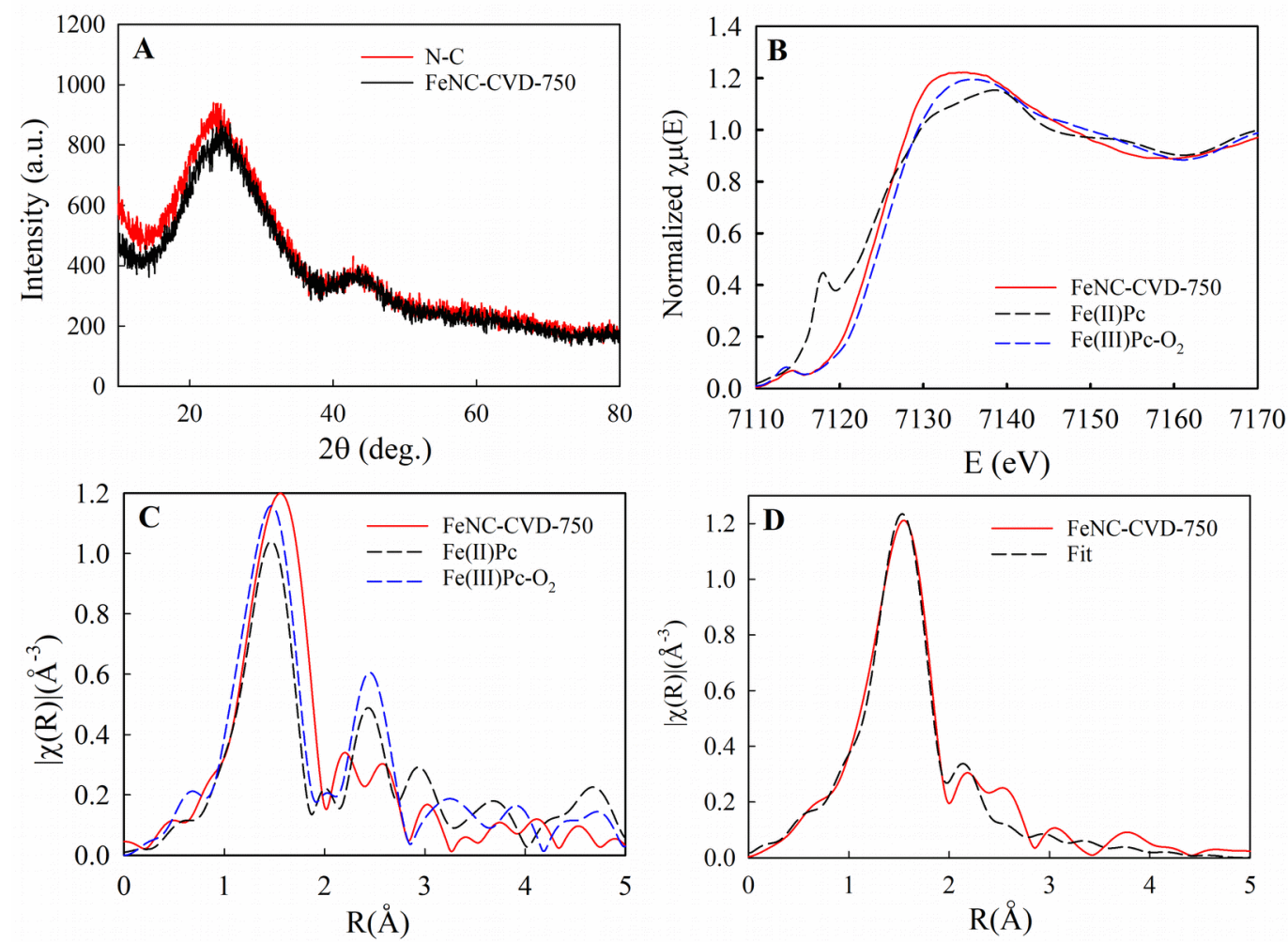

Figure 3. (A) XRD of the N-C and FeNC-CVD-750, (B) Ex situ XANES and (C) FT-EXAFS of FeNC-CVD-750, and Iron(II) phthalocyanine (Fe(II)Pc) and Iron(III) phthalocyanine tetrasulfonic acid (Fe(III)Pc- $\mathrm{O}_{2}$ ) standards, for comparison, and (D) Fitting results for the ex situ EXAFS of FeNC-CVD-750.

\section{Discussion}


A high density of Fe- $\mathrm{N}_{4}$ sites in FeNC-CVD-750 is realized by using a CVD synthesis method for which the thermal evolution pathway of the $\mathrm{Fe}(\mathrm{II})-\mathrm{N}_{4}$ moiety during heat treatment is fundamentally different from that for the mixture of the $\mathrm{Fe}, \mathrm{N}$, and $\mathrm{C}$ precursors. Using the in-temperature XAS technique, we recently revealed that the thermal evolution pathway of the Fe(II)- $\mathrm{N}_{4}$ moiety in the mixture of the $\mathrm{Fe}, \mathrm{N}$, and $\mathrm{C}$ precursors is: Fe compounds $\rightarrow \mathrm{Fe}_{2} \mathrm{O}_{3} \rightarrow$ tetrahedral Fe(II)- $\mathrm{O}_{4} \rightarrow$ in-plane $\mathrm{Fe}(\mathrm{II})-\mathrm{N}_{4}$ (22). The last step is initiated at $\sim 600{ }^{\circ} \mathrm{C}$ and promoted with increasing temperature until 1000 ${ }^{\circ} \mathrm{C}$, forming more $\mathrm{Fe}(\mathrm{II})-\mathrm{N}_{4}$ sites. This is likely because the Fe has higher affinity toward oxygen than nitrogen, and thus a higher temperature is needed to overcome the difference in thermodynamic stability between $\mathrm{Fe}(\mathrm{II})-\mathrm{O}_{4}$ and $\mathrm{Fe}(\mathrm{II})-\mathrm{N}_{4}$. As a result, the highest ORR activity was obtained at a pyrolysis temperature of $\sim 1000{ }^{\circ} \mathrm{C}$ for the mixed Fe, $\mathrm{N}$, and C precursors. At even higher temperature of $1100{ }^{\circ} \mathrm{C}$, the ORR activity drops as the $\mathrm{Fe}(\mathrm{II})$ $\mathrm{N}_{4}$ sites decompose, reducing the site density (9). As a result, the optimized pyrolysis temperature for the mixture of Fe, $\mathrm{N}$, and $\mathrm{C}$ precursors is $1000 \pm 100{ }^{\circ} \mathrm{C}(5,8-10,15,16)$. Such high temperature however severely limits the density of the Fe(II)- $\mathrm{N}_{4}$ sites in Fe-N$\mathrm{C}$ since the nitrogen content sharply drops as the temperature increases from $600{ }^{\circ} \mathrm{C}$ to $1000{ }^{\circ} \mathrm{C}(8,10)$. On the other hand, the $\mathrm{Fe}(\mathrm{II})-\mathrm{N}_{4}$ site is directly formed via deposition of gas phase $\mathrm{FeCl}_{3}$ into the micropores of the $\mathrm{N}$-C substrate during CVD, without transitioning through $\mathrm{Fe}(\mathrm{II})-\mathrm{O}_{4}$. It is thus unnecessary to reach $1000{ }^{\circ} \mathrm{C}$ to drive the formation of $\mathrm{Fe}(\mathrm{II})-\mathrm{N}_{4}$. Using the vapor deposition approach, the highest ORR activity is observed using a low heat treatment temperature of $750{ }^{\circ} \mathrm{C}$. The ORR activity of FeNCCVD-750 is far superior to that of the FeNC-CVD-1000 in a RDE, and the intensity of the redox $\mathrm{Fe}^{3+2+}$ peaks is also much higher. These results suggest that FeNC-CVD-750 
possesses a higher density of Fe- $\mathrm{N}_{4}$ sites than FeNC-CVD-1000 because the $\mathrm{Fe}(\mathrm{II})-\mathrm{N}_{4}$ sites are better preserved at lower temperature. Elimination of high temperature pyrolysis made possible by the CVD method greatly enhances the Fe(II)- $\mathrm{N}_{4}$ site density compared to that of Fe-N-C formed by pyrolyzing the mixture of $\mathrm{Fe}, \mathrm{N}$, and $\mathrm{C}$ precursors at high temperatures.

Another possible advantage of the CVD method is that the Fe(II)- $\mathrm{N}_{4}$ sites are selectively formed on the surface of the $\mathrm{N}-\mathrm{C}$ and are thus accessible to the electrochemical reaction. On the other hand, the $\mathrm{Fe}(\mathrm{II})-\mathrm{N}_{4}$ sites are likely uniformly distributed throughout the whole carbon matrix in the conventional Fe-N-C catalysts, given that the Fe, N, C precursors are sufficiently mixed before pyrolysis, either by wet chemical impregnation or dry ball milling. The new vapor deposition route demonstrated here for the synthesis of Fe-N-C with highly dense $\mathrm{Fe}(\mathrm{II})-\mathrm{N}_{4}$ sites can be extended to single atom catalysis for a broad range of applications.

\section{Methods}

\section{Synthesis}

Chemicals: 1,10-phenanthroline monohydrate, anhydrous Iron(III) chloride ( $\mathrm{FeCl}_{3}, 99 \%$ ), iron(II) phthalocyanine (Fe(II)Pc, 95\%), Iron(III) phthalocyanine-tetrasulfonic acid ( $\mathrm{Fe}(\mathrm{III}) \mathrm{Pc}-\mathrm{O}_{2}, 80 \%$ ), zinc oxide ( $\left.\mathrm{ZnO}\right), 2$-methylimidazole, and sulfuric acid $\left(\mathrm{H}_{2} \mathrm{SO}_{4}, 95\right.$ 97\%, PPT Grade) were all purchased from Sigma-Aldrich. All aqueous solutions were prepared using deionized (DI) water $(18.2 \mathrm{M} \Omega \cdot \mathrm{cm})$ obtained from an ultra-pure purification system (Aqua Solutions).

Synthesis of zeolitic imidazolate framework eight (ZIF-8). $200 \mathrm{ml}$ methanolic solution with dissolved $\mathrm{Zn}\left(\mathrm{NO}_{3}\right) \cdot 6 \mathrm{H}_{2} \mathrm{O}$ (2.933 g) was added to $200 \mathrm{ml}$ methanolic solution of 2- 
methylimidazole (6.489 g). The solution was mixed using magnetic stirring for one hour. The mixture was then left at room temperature for 24 hours without stirring. The resultant white suspension was washed three times by centrifuging with methanol and then dried at $40{ }^{\circ} \mathrm{C}$ in a vacuum oven overnight.

Synthesis of N-C: The mixture of $1.0 \mathrm{~g}$ ZIF-8 and $0.25 \mathrm{~g} 1,10$ phenanthroline was ball milled for two hours in a plastic container with five plastic balls with a diameter of 0.25 inches. The resulting powders were pyrolyzed under $\mathrm{Ar}$ at $1050{ }^{\circ} \mathrm{C}$ for one hour with a ramp rate to $1050{ }^{\circ} \mathrm{C}$ of $5{ }^{\circ} \mathrm{C}$ per minute, followed by natural cooling to room temperature. The powders collected are labelled as N-C and were used for the subsequent non-contact pyrolysis synthesis of Fe-N-C.

Chemical vapor deposition: A boat containing $40 \mathrm{mg}$ of anhydrous $\mathrm{FeCl}_{3}$ was placed in a quartz tube upstream in the gas flow of a boat containing $60 \mathrm{mg}$ of $\mathrm{N}-\mathrm{C}$. The $\mathrm{N}-\mathrm{C}$ was spread in a thin layer of around $8 \mathrm{~cm}$ length. The two boats were approximately $1 \mathrm{~cm}$ apart. The furnace was heated to $750{ }^{\circ} \mathrm{C}$ with a ramp rate of $25{ }^{\circ} \mathrm{C}$ per minute and then the temperature was held at $750{ }^{\circ} \mathrm{C}$ for three hours, followed by cooling to room temperature naturally. The powders were then collected from the furnace and subjected to magnetic purification by slowly moving a small magnet $\sim 0.5 \mathrm{~cm}$ above the powder to remove Fe nanoparticles. The purified powders were labelled FeNC-CVD-750 and subjected to RDE and PEMFC evaluations.

Electrochemical characterization-RDE. The catalyst powders were deposited on a glassy carbon working electrode. Catalyst inks were prepared by dispersing $10 \mathrm{mg}$ of the catalyst powder in a mixture of Millipore water (36.5 $\mu \mathrm{L}, 18.2 \mathrm{M} \Omega \mathrm{cm}$ ) and ethanol (300 $\mu \mathrm{L}$, Sigma-Aldrich, 99.8\%) into which 5 wt\% Nafion solution (108.5 $\mu \mathrm{L}$, Sigma- 
Aldrich) was added as a binder phase. The resulting mixture was sonicated for $60 \mathrm{~min}$, and then an aliquot of $8.8 \mu \mathrm{L}$ was drop-cast onto the glassy carbon electrode $\left(0.2463 \mathrm{~cm}^{2}\right.$, Pine instrument), resulting in a catalyst loading of $800 \mu \mathrm{g} \cdot \mathrm{cm}^{-2}$. The working electrode with the deposited catalyst layer was used in a three-electrode cell set-up connected to a bipotentiostat (Biologic SP 300) and rotator (Pine Instruments). A graphite rod and reversible hydrogen electrode (RHE) were used as counter and reference electrodes, respectively. The ORR activity was measured in room-temperature $\mathrm{O}_{2}$-saturated $0.5 \mathrm{M}$ $\mathrm{H}_{2} \mathrm{SO}_{4}$ in a voltammetric steps from 0.05 to $0.95 \mathrm{~V}$ vs. RHE via steady-state by using a 20-mV potential step and 25-s potential hold time at every step with a rotation rate of $900 \mathrm{rpm}$ at room-temperature. The cyclic voltammetry $(\mathrm{CV})$ was carried out between 0.05 to $0.95 \mathrm{~V} v s$. RHE with a scan rate of $10 \mathrm{mV} \cdot \mathrm{s}^{-1}$ in $\mathrm{N}_{2}$-saturated $0.5 \mathrm{M} \mathrm{H}_{2} \mathrm{SO}_{4}$.

Electrochemical characterization-PEMFC. The FeNC-CVD-750 catalyst was used to prepare the cathode for MEA tests in a PEMFC under $\mathrm{H}_{2}-\mathrm{O}_{2}$ conditions. Catalyst ink containing $50 \mathrm{wt} \%$ of Nafion ${ }^{\circledR}$ was made by ultrasonically mixing the catalyst, isopropanol, de-ionized water, and $5 \% \mathrm{Nafion}{ }^{\circledR}$ suspension in alcohols at a 1:20:20:20 weight ratio for three hours. The inks were blade coated on one side of a gas diffusion layer (SGL-29BC, Fuel Cell Store) until the cathode catalyst loading reached $\sim 4.0$ $\mathrm{mg} \cdot \mathrm{cm}^{-2}$. A thin Nafion layer was sprayed on top of cathode catalyst layer to mitigate the interfacial resistance. commercial Pt-catalyzed gas diffusion electrode (GDE, 0.3 $\mathrm{mg}_{\mathrm{Pt}} \mathrm{Cm}^{2}$, Fuel Cell Store) was used at the anode, and it was hot pressed on NR-212 Nafion membrane at $130{ }^{\circ} \mathrm{C}$ for 4 minutes. The cathode electrode was then hot pressed on the other side of the NR-212 membrane at $130{ }^{\circ} \mathrm{C}$ for 2 minutes. The full catalyst-coated membrane, which had an active geometric area of $5.0 \mathrm{~cm}^{2}$, was assembled into a single 
cell with single-serpentine flow channels. The single cell was then evaluated in a fuel cell test station (100 W, Scribner 850e, Scribner Associates). The cells were conditioned under $\mathrm{N}_{2} / \mathrm{N}_{2}$ at $100 \%$ relative humidity and $80{ }^{\circ} \mathrm{C}$ for two hours. Oxygen flowing at 2000 sccm and $\mathrm{H}_{2}$ (purity 99.999\%) flowing at $500 \mathrm{sccm}$ were used as the cathode and anode reactants, respectively. The back pressures during the fuel cell tests are 1.0 bar reactant gas, following US Department of Energy protocols (2). Fuel cell polarization curves were recorded in a voltage control mode. All the cathode catalyst layers contain $50 \mathrm{wt} \%$ of Nafion.

\section{Physical characterizations.}

TEM: Transmission electron microscopy (TEM) was conducted on a Probe-corrected FEI Titan Themis $300 \mathrm{~S} / \mathrm{TEM}$ with an acceleration voltage of $300 \mathrm{kV}$ with samples deposited on a holey carbon film on a 300 mesh copper grid.

SEM: Scanning electron microscopy (SEM) micrographs of N-C were obtained with a Hitachi S-4800 apparatus (Hitachi, Tokyo, Japan).

XRD: X-ray diffraction (XRD) patterns were conducted using a PANanalytical X'Pert Pro powder X-ray diffractometer with $\mathrm{Cu} \mathrm{K}_{\alpha}$ radiation.

$\underline{\mathrm{N}_{2}}$ adsorption/desorption analysis: $\mathrm{N}_{2}$ sorption analysis was performed at liquid nitrogen temperature (77 K) with a Micromeritics ASAP 2020 instrument. Prior to the measurements, all samples were degassed at $200{ }^{\circ} \mathrm{C}$ for $5 \mathrm{~h}$ in flowing nitrogen to remove guest molecules or moisture. The pore size distributions were calculated by fitting the full isotherm with the quench solid density functional theory model with slit pore geometry from NovaWin (Quantachrome Instruments). 
XAS data collection and analysis. The preparation method of the XAS electrodes can be referred to our previous work $(26,27)$. The ex situ XAS experiments were conducted at room temperature in a previously described flow half-cell. The data at the Fe K-edge of the samples were collected in the transmission mode at the beamline 6-BM of the National Synchrotron Light Source (NSLS) II, Brookhaven National Laboratory (BNL). Typical experimental procedures were utilized with details provided in our previous work $(26,27)$.

\section{Acknowledgements}

This work was supported by the US Department of Energy under award number DEEE0008416 and DE-EE0008075. The authors acknowledge the support from the DOE Energy Efficiency and Renewable Energy Fuel Cell Technologies Office (DOE-EEREFCTO) ElectroCat consortium. This research used beamline 6-BM, 7-BM and 8-ID (ISS) of the National Synchrotron Light Source II, a U.S. Department of Energy (DOE) Office of Science User Facility operated for the DOE Office of Science by Brookhaven National Laboratory under Contract No. DE-SC0012704. Argonne is a U.S. Department of Energy

Office of Science Laboratory operated under Contract No. DE-AC02-06CH11357 by UChicago Argonne, LLC.

\section{Competing financial interests}

The authors declare no competing financial interests.

\section{References}


1. T. Yoshida, K. Kojima, Toyota MIRAI Fuel Cell Vehicle and Progress Toward a Future Hydrogen Society. The Electrochemical Society Interface 24, 45-49 (2015).

2. S. T. Thompson, A. R. Wilson, P. Zelenay, D. J. Myers, K. L. More, K. C. Neyerlin, D. Papageorgopoulos, ElectroCat: DOE's approach to PGM-free catalyst and electrode R\&D. Solid State Ionics 319, 68-76 (2018).

3. X. Wan, X. Liu, Y. Li, R. Yu, L. Zheng, W. Yan, H. Wang, M. Xu, J. Shui, Fe-N-C electrocatalyst with dense active sites and efficient mass transport for highperformance proton exchange membrane fuel cells. Nature Catalysis 2, 259-268 (2019).

4. D. Banham, T. Kishimoto, Y. Zhou, T. Sato, K. Bai, J.-i. Ozaki, Y. Imashiro, S. Ye, Critical advancements in achieving high power and stable nonprecious metal catalyst-based MEAs for real-world proton exchange membrane fuel cell applications. Science Advances 4, eaar7180 (2018).

5. H. T. Chung, D. A. Cullen, D. Higgins, B. T. Sneed, E. F. Holby, K. L. More, P. Zelenay, Direct atomic-level insight into the active sites of a high-performance PGMfree ORR catalyst. Science 357, 479-484 (2017).

6. J. Li, M. Chen, D. A. Cullen, S. Hwang, M. Wang, B. Li, K. Liu, S. Karakalos, M. Lucero, H. Zhang, C. Lei, H. Xu, G. E. Sterbinsky, Z. Feng, D. Su, K. L. More, G. Wang, Z. Wang, G. Wu, Atomically dispersed manganese catalysts for oxygen reduction in proton-exchange membrane fuel cells. Nature Catalysis 1, 935-945 (2018).

7. A. Zitolo, N. Ranjbar-Sahraie, T. Mineva, J. Li, Q. Jia, S. Stamatin, G. F. Harrington, S. M. Lyth, P. Krtil, S. Mukerjee, E. Fonda, F. Jaouen, Identification of catalytic sites in 
cobalt-nitrogen-carbon materials for the oxygen reduction reaction. Nat. Commun. 8, 957 (2017).

8. H. Zhang, S. Hwang, M. Wang, Z. Feng, S. Karakalos, L. Luo, Z. Qiao, X. Xie, C. Wang, D. Su, Y. Shao, G. Wu, Single Atomic Iron Catalysts for Oxygen Reduction in Acidic Media: Particle Size Control and Thermal Activation. J. Am. Chem. Soc. 139, 14143-14149 (2017).

9. M. Lefèvre, E. Proietti, F. Jaouen, J.-P. Dodelet, Iron-Based Catalysts with Improved Oxygen Reduction Activity in Polymer Electrolyte Fuel Cells. Science 324, 71-74 (2009).

10. E. Proietti, F. Jaouen, M. Lefèvre, N. Larouche, J. Tian, J. Herranz, J.-P. Dodelet, Iron-based cathode catalyst with enhanced power density in polymer electrolyte membrane fuel cells. Nat. Commun. 2, 416 (2011).

11. R. Jasinski, A New Fuel Cell Cathode Catalyst. Nature 201, 1212 (1964).

12. S. Gupta, D. Tryk, I. Bae, W. Aldred, E. Yeager, Heat-treated polyacrylonitrile-based catalysts for oxygen electroreduction. J. Appl. Electrochem. 19, 19-27 (1989).

13. U. Tylus, Q. Jia, K. Strickland, N. Ramaswamy, A. Serov, P. Atanassov, S. Mukerjee, Elucidating Oxygen Reduction Active Sites in Pyrolyzed Metal-Nitrogen Coordinated Non-Precious-Metal Electrocatalyst Systems. J. Phys. Chem. C 118, 8999-9008 (2014).

14. A. Serov, K. Artyushkova, E. Niangar, C. Wang, N. Dale, F. Jaouen, M.-T. Sougrati, Q. Jia, S. Mukerjee, P. Atanassov, Nano-structured non-platinum catalysts for automotive fuel cell application. Nano Energy 16, 293-300 (2015). 
15. J. Li, S. Ghoshal, W. Liang, M.-T. Sougrati, F. Jaouen, B. Halevi, S. McKinney, G. McCool, C. Ma, X. Yuan, Z.-F. Ma, S. Mukerjee, Q. Jia, Structural and mechanistic basis for the high activity of Fe-N-C catalysts toward oxygen reduction. Energy Environ. Sci. 9, 2418-2432 (2016).

16. H. Zhang, H. T. Chung, D. A. Cullen, S. Wagner, U. I. Kramm, K. L. More, P. Zelenay, G. Wu, High-performance fuel cell cathodes exclusively containing atomically dispersed iron active sites. Energy Environ. Sci. 12, 2548-2558 (2019).

17. J. Li, A. Alsudairi, Z.-F. Ma, S. Mukerjee, Q. Jia, Asymmetric Volcano Trend in Oxygen Reduction Activity of Pt and Non-Pt Catalysts: In Situ Identification of the Site-Blocking Effect. J. Am. Chem. Soc. 139, 1384-1387 (2017).

18. H. Xu, D. Cheng, D. Cao, X. C. Zeng, A universal principle for a rational design of single-atom electrocatalysts. Nature Catalysis 1, 339-348 (2018).

19. R. Chen, H. Li, D. Chu, G. Wang, Unraveling Oxygen Reduction Reaction Mechanisms on Carbon-Supported Fe-Phthalocyanine and Co-Phthalocyanine Catalysts in Alkaline Solutions. J. Phys. Chem. C 113, 20689-20697 (2009).

20. A. Zitolo, V. Goellner, V. Armel, M.-T. Sougrati, T. Mineva, L. Stievano, E. Fonda, F. Jaouen, Identification of catalytic sites for oxygen reduction in iron- and nitrogendoped graphene materials. Nat. Mater. 14, 937 (2015).

21. H. A. Gasteiger, S. S. Kocha, B. Sompalli, F. T. Wagner, Activity benchmarks and requirements for Pt, Pt-alloy, and non-Pt oxygen reduction catalysts for PEMFCs. Appl. Catal. B-Environ. 56, 9-35 (2005).

22. L. Jingkun, J. Li, W. Evan, L. R. Lynne K., L. Ershuai, Z. andrea, S. Moulay-Tahar, M. Sanjeev, Z. Zipeng, H. Yu, Y. Fan, Z. Sichen, X. Hui, K. A. Jeremy, J. Frederic, M. 
Deborah J., J. Qingying, The Evolution Pathway from Iron Compounds to Fe1(II)-N4 Sites Through Gas-Phase Iron During Pyrolysis. (2019). Preprint available at ChemRvix

23. D. E. Beltrán, S. Litster, Half-Wave Potential or Mass Activity? Characterizing Platinum Group Metal-Free Fuel Cell Catalysts by Rotating Disk Electrodes. ACS Energy Letters 4, 1158-1161 (2019).

24. G. Wu, K. L. More, C. M. Johnston, P. Zelenay, High-Performance Electrocatalysts for Oxygen Reduction Derived from Polyaniline, Iron, and Cobalt. Science 332, 443447 (2011).

25. Q. Jia, N. Ramaswamy, H. Hafiz, U. Tylus, K. Strickland, G. Wu, B. Barbiellini, A. Bansil, E. F. Holby, P. Zelenay, S. Mukerjee, Experimental Observation of RedoxInduced Fe-N Switching Behavior as a Determinant Role for Oxygen Reduction Activity. ACS Nano 9, 12496-12505 (2015).

26. Q. Jia, W. Liang, M. K. Bates, P. Mani, W. Lee, S. Mukerjee, Activity Descriptor Identification for Oxygen Reduction on Platinum-Based Bimetallic Nanoparticles: In Situ Observation of the Linear Composition-Strain-Activity Relationship. Acs Nano 9, 387-400 (2015).

27. Q. Jia, J. Li, K. Caldwell, D. E. Ramaker, J. M. Ziegelbauer, R. S. Kukreja, A. Kongkanand, S. Mukerjee, Circumventing Metal Dissolution Induced Degradation of Pt-Alloy Catalysts in Proton Exchange Membrane Fuel Cells: Revealing the Asymmetric Volcano Nature of Redox Catalysis. ACS Catal. 6, 928-938 (2016). 